\title{
Dyanmic geomorphology characteristics research near the tidal flat of the Liangduo River Gate, Jiangsu
}

\author{
Chen Jun \\ College of Harbor,Coastal and Offshore Engineering \\ Hohai University \\ Nanjing, China \\ Junchen@hhu.edu.cn
}

\begin{abstract}
The study area is the tidal flat of the Liangduo River Gate, which is located on the Jiangsu coast. It uses the field measurement data and the remote sensing data to analyse the dynamic geomorphology and development characteristics. The results show that the tidal current is strong and the suspended sediment concentration is large. The geomorphology of the tidal creeks changes frequently and the tidal flat development has became from accretion to erosion in recent years. The results will guide the coastal reclamation engineering in the future.
\end{abstract}

Index Terms - dynamic geomorphology, intertidal flat, sand ridges, Jiangsu coast.

\section{STUDY AREA}

The study area is located on the Jiangsu coast, China, which is situated between the Yangtze River estuary and the aboudonded Yellow River mouth. Muddy coast is more than $90 \%$. Total area of the tidal flat is about $5000 \mathrm{~km}^{2}$ which is about $1 / 4$ of the total area in China. The development process of the muddy coast is special because the sediment source came from the ancient Yellow River and the ancient Yangtze River during 1128-1855. The hydrodynamic environment is controlled by the rotary tidal wave system of the South Yellow Sea and the advancing tidal wave system of the East China Sea. This two tidal wave systems meet at the Tiaozini Sandbank. Under the special hydrodynamic environment and abundant sediment supplyment, the area of the Tiaozini Sandbank becomes the largest one of the Radial Sand Ridges with the most complicated topography. The intertidal flat is in a marcotidal area, with an average tidal range of 3.9-5.5 m, and a regularly semi-diurnal tide ${ }^{[1]}$. The tidal flat is broad and the average width of the intertidal flat is about $12 \mathrm{~km}$. Its slope is gentle and the average gradient is about $0.2 \% 0-0.5 \%$. Typically, the intertidal flat is covered with Suaeda glauca Bunge, suaeda maritime Dumort and Spartina angilica over the upper intertidal area; mud flats, mixed flats and silt-sand flats form the mid-lower intertidal areas ${ }^{[2]}$. The study area is located on the north edge of the Tiaozini Sandbank, where the Xiyang tidal channel extends into the Tiaozini Sandbank (Fig. 1).

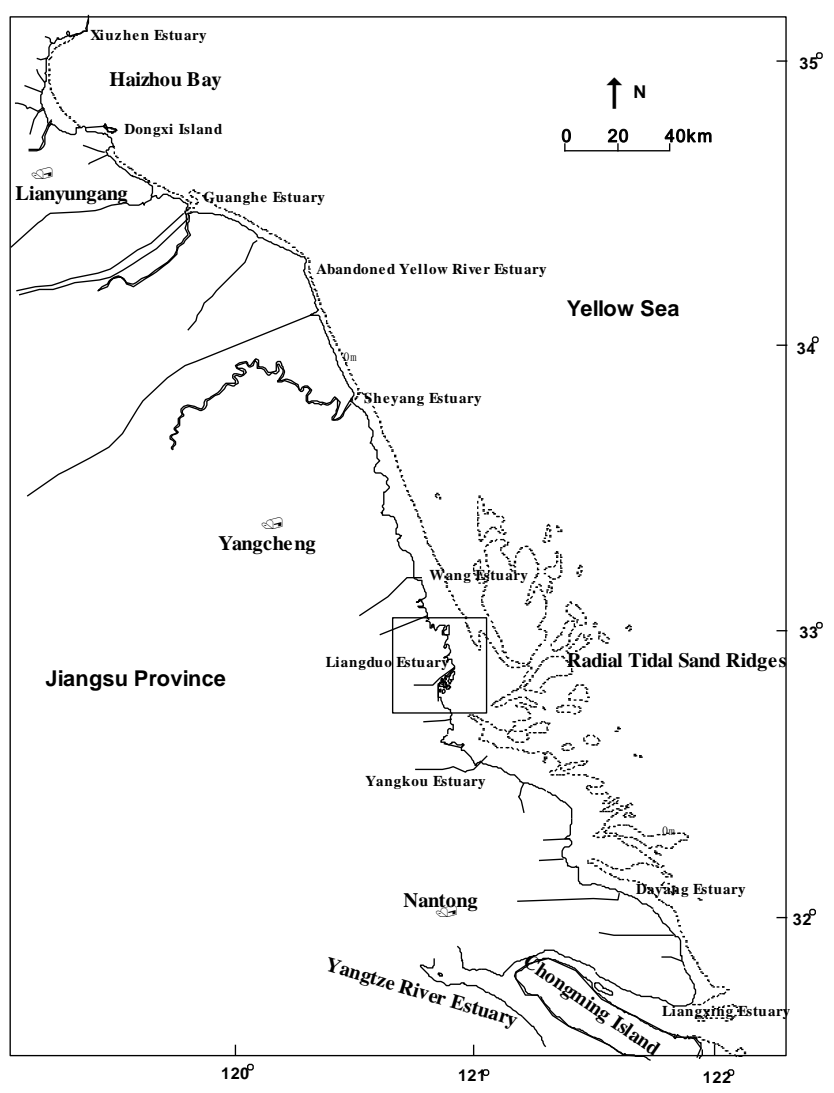

Fig. 1. the study area

\section{METHODS}

In this paper, it used the field measurement data and the remote sensing data to analyse the dynamic geomorphology and development characteristics. In situ field measurements were undertaken, at station Y11 and Y12 in the Xiyang tidal channel on August 24, 2006 (Fig. 2). It measured the vertical velocity and the suspended sediment concentration through ADCP. The seabed leveling was undertaken along the profile 
from the upper to the lower intertidal flat on September, 2007 and October, 2008.

The remote sensing data were collected from 1969 to 2013. The registration and accuracy inspection of the remote sensing satellite images were done through the field locating information. The sandbank and the tidal creeks were drawn after the image digitalizing. The coast lines in different periods were contrasted by Mapinfo Professional.

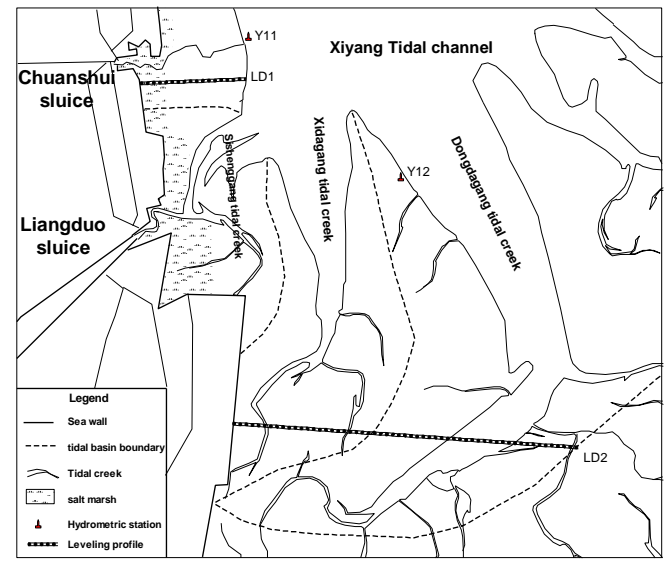

Fig. 2. the hydrological station and the leveling profile

\section{RESULTS}

\section{Geomorphology Characteristics}

Tidal flat is a particular geomorphic system on the broad tidla flat ${ }^{[3]}$. The flood tidal current comes from the open sea not only through the tidal creeks but also through the lower tidal flat. But the ebb tidal current is not like this. At the beginning of the ebb, if the water body is very thick on the tidal flat, the ebb tidal current leaves through both the tidal creeks and the lower tidal flat. However, when the thickness of the water body becomes thin, the current friction coming from the tidal flat will play an important role. The gravity becomes the main factor to control the water movement. The current flows along the road which has the largest slope. So the water on the tidal flat converges to the main tidal creeks. The depth of the water body in this enviroment is named groove water depth which means the water turns from planar flow to streamline flow. The groove water depth is influenced by the grain size of the sediment, the slope of the tidal flat, the microtopography, the poriness and so on. It changes between $0.05 \mathrm{~m}$ and $0.15 \mathrm{~m}$. On the broad tidal flat, there are a lot of tidal creeks transporting the water from the tidal flat to the open sea. The tidal creeks often distribute vertically to the coast and usually have the independent tidal basin. The tidal flat ridges between two tidal basins divide the tidal flat into several tidal basins ${ }^{[4]}$.

The north study edge is the tidal channel of the Chuanshuigang sluice and the south is the Erfenshui tidal ridges on the Tiaozini sandbank. There are four larger tidal creeks distributing on the tidal flat near the Liangduohe sluice. This four tidal creeks extend from the Spartina angilica tidal flat, mud flats, silt-sand flats to the Xiyang tidal channel. So the tidal flat is divided into four tidal basins (Fig.2).

Chuanshuigang tidal creek is the sluice water way of the Dongtaihe sluice in the north area. The length of the tidal creek is about $8 \mathrm{~km}$ and extends from east to west.

The Sishenggang is the main tidal creek in the study area, which has the typical dendritical structure. The length of the main stem is about $15 \mathrm{~km}$ and the width of the entrance is about $2.5 \mathrm{~km}$. The Liangduohe sluice channel connects with the Sishenggang tidal creek at the distance of about $4.5 \mathrm{~km}$ to the sluice. The area of the Sishenggang tidal basin is about $57.65 \mathrm{~km}^{2}$, which includes the tidal saltmarsh area about 16.55 $\mathrm{km}^{2}$ and the tidal creek area about $9.9 \mathrm{~km}^{2}$.

The north branch of the Xidagang tidal creek and the Dongdagang tidal creek is maily located on the north of the Tiaozini sandbank, which is parallel with the seawall. The length of the main stem is about $30 \mathrm{~km}$ and the width of the entrance is about $5 \mathrm{~km}$. The shape of the tidal creek is the Vshaped. They are the main tidal creeks from Xiyang tidal channel to the Tiaozini sandbank.

\section{Hydrology Characteristics}

The tidal range of the study area was large and the largest tidal range from the field data was about $6 \mathrm{~m}$. The ebb duration was larger than the flood. The flood duration decreases and the ebb duration increases from north to south. The flood duration of the station Y11 and Y12 was about 5h40m and $4 \mathrm{~h} 40 \mathrm{~m}$ respectively. The ebb duration of the station Y11 and Y12 was about $6 \mathrm{~h} 30 \mathrm{~m}$ and $7 \mathrm{~h} 30 \mathrm{~m}$ respectively.

The hydrodynamic force was very strong at the Radial tidal ridge sea area ${ }^{[1]}$. The largest value of the tidal current velocity was at the Xiyang tidal channel. The flood tidal current mean velocity was about $1.3 \mathrm{~m} / \mathrm{s}$ and the ebb was about $0.85 \mathrm{~m} / \mathrm{s}$. The flood tidal current mean velocity was larger than the ebb (Fig. 3, Tab. 1). The vertical distribution pattern of the tidal current velocity was that the value decreased from the surface layer to the bottom layer. The largest value of the flood and ebb tidal current velocity appeared at the surface layer of station Y12 in the spring tide, which was about $3.34 \mathrm{~m} / \mathrm{s}$ and $1.51 \mathrm{~m} / \mathrm{s}$ respectively. The tidal current was the rectilinear current and the movement direction was northwest-southeast along the deep channel.

The suspended sediment concentration was higher at the Radial tidal ridge sea area on the whole ${ }^{[1]}$. The largest uspended sediment concentration area was at the study area. The flood mean suspended sediment concentration was about $0.9 \mathrm{~kg} / \mathrm{m}^{3}$ and the ebb was about $1.2 \mathrm{~kg} / \mathrm{m}^{3}$. The flood mean suspended sediment concentration was larger than the ebb (Tab. 1, Fig. 3). The vertical distribution pattern of the suspended sediment concentration was different to the vertical distribution pattern of the tidal current velocity. The suspended sediment concentration value decreased from the bottom layer to the surface layer. The maximal value appeared at the $0.8 \mathrm{H}$ layer of the station Y12, which was $3.12 \mathrm{~kg} / \mathrm{m}^{3}$.

The direction of the tidal flux was the same to the residual current direction. The tidal flux was $14.3 \times 10^{4}$ cubic meters and $8.1 \times 10^{4}$ cubic meters at the station Y11 and Y12 respectively. 
The flux of suspended sediment concentration was about 97.7 $\mathrm{t} / \mathrm{m}$ and $32.1 \mathrm{t} / \mathrm{m}$ at the station $\mathrm{Y} 11$ and $\mathrm{Y} 12$ respectively. The direction was southeastward and northeastward. According to the tidal current and suspended sediment numerical model of the Radial Sandridges sea area, there was the anticlockwise circulation at the study area. The suspended sediment was transported to the northeast and southeast through the Doufuzhayaomen tidal channel.

Tab.1 Characteristic value of the current velocity and the suspended sediment concentration at Station Y11 and Y12 in the summer spring

\begin{tabular}{|c|c|c|c|c|c|c|}
\hline \multirow{2}{*}{ station } & \multicolumn{3}{|c|}{$\begin{array}{c}\text { Mean velocity in vertical } \\
(\mathrm{m} / \mathrm{s})\end{array}$} & \multicolumn{2}{|c|}{$\begin{array}{c}\text { Mean sediment concentration } \\
\text { in vertical }\left(\mathrm{kg} / \mathrm{m}^{3}\right)\end{array}$} \\
\cline { 2 - 7 } & flood & ebb & tide & flood & ebb & tide \\
\hline Y11 & 1.26 & 0.88 & 1.11 & 0.84 & 0.92 & 0.87 \\
\hline Y12 & 1.31 & 0.82 & 1.01 & 0.96 & 1.14 & 1.04 \\
\hline station & \multicolumn{2}{|c|}{$\begin{array}{c}\text { Tidal flux } \\
\left(\times 10^{4} \text { cubic / } \mathrm{m}\right)\end{array}$} & $\begin{array}{c}\text { Direction } \\
\left({ }^{\circ}\right)\end{array}$ & $\begin{array}{c}\text { Suspended } \\
\text { sediment flux } \\
(\mathrm{t} / \mathrm{m})\end{array}$ & $\begin{array}{c}\text { Direction } \\
\left({ }^{\circ}\right)\end{array}$ \\
\hline Y11 & \multicolumn{2}{|c|}{14.3} & 142 & 97.7 & 141 \\
\hline Y12 & \multicolumn{2}{|c|}{8.1} & 107 & 32.1 & 79 \\
\hline
\end{tabular}
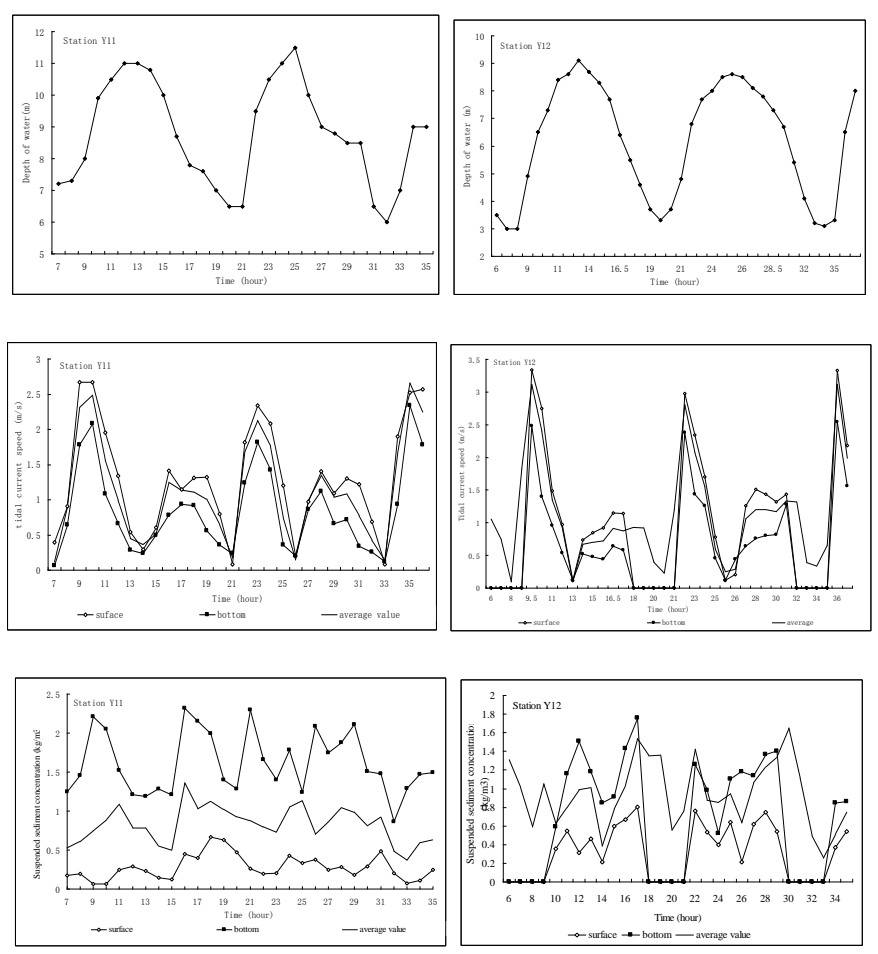

Fig. 3. measurement data of the hydrographic station

\section{Development Characteristics}

The study area was located in the junction of Tiaozini sandbank and the Xiyang tidal channel, which was the largest sandbank and the largest channel of the Radial Sandridges respectively. The graphical position was special and the development history was long. Before this century, the tidal flat of the study area was in the physical processes of accretion because of the abundant suspended sediments. The tidal current direction from the abandoned Yellow River Delta to the Tiaozini sandbank was southward or southwestward and the flood tidal current speed was larger than the ebb. In addition, there were strong NE winds. So the littoral current formed and flowed from the north to south. The abundant suspended sediments eroded from the abandoned Yellow River Delta were transported to the Radial Sandridges area.

Furthermore, abundant suspended sediments were also supplied from the adjoining sea, e.g. the offshore sand ridge areas, which was transported by advection during the flood period $^{[6]}$. Following to the principle of scour delay effect and sedimentation delay effect, these sediments deposited continuously and the tidal flat accreted seawards continuously. The section shape was typical convex in this tidal flat(Fig.4).

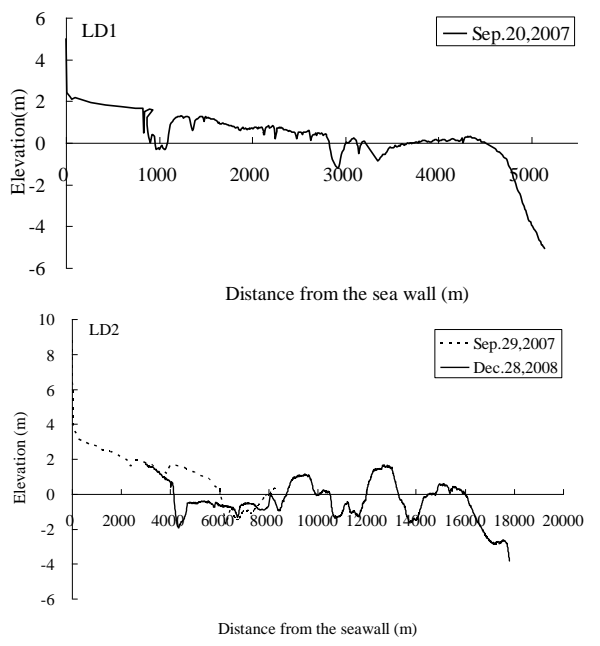

Fig. 4. Seabed elevation changes along profile LD1 and LD2

In recent years, the tidal flat has began to appear the trend of erosion. Through contrast the remote sensing image in 1973 with the image in 2013, it can be seen, the tidal flat edge of the study area was eroded landwards about $5 \mathrm{~km}$. The erosion phenomenon first appeared in 2005. Then, the average annual erosion rate was about $400 \mathrm{~m}$ between 2005 and 2008. But the tidal flat was stable since 2008.

The dynamic changes of the tidal creeks were more obvious than the tidal flat. The Sishenggang connected with the Xiyang northeastwards and the Liangduohe sluice water way was one of the branch of the Sishenggang tidal creek. Although the location of the Liangduohe sluice water way and the Sishenggang tidal creek was almost stationary and the tidal basin area changed little between 1973 and 2013, they were constantly moving. The movement of the Sishenggang tidal creek has experienced four periodic processes at least. It development pattern had such stages. The first stage was the eastwards movement of north branch of the the Xidagang tidal channel. Then, the tidal curent eroded the north area of the Tiaozini sandbank and the new north-south tidal creek formed. This tidal creek moved northwestwards and in turn captured the Sishenggang tidal creek, Liangduihe sluice water way, Chuanshuigang tidal creek. When this tidal creek moved northwestwards, a new tidal creek formed in the original position. Fig. 5 showed the latest capture process. 

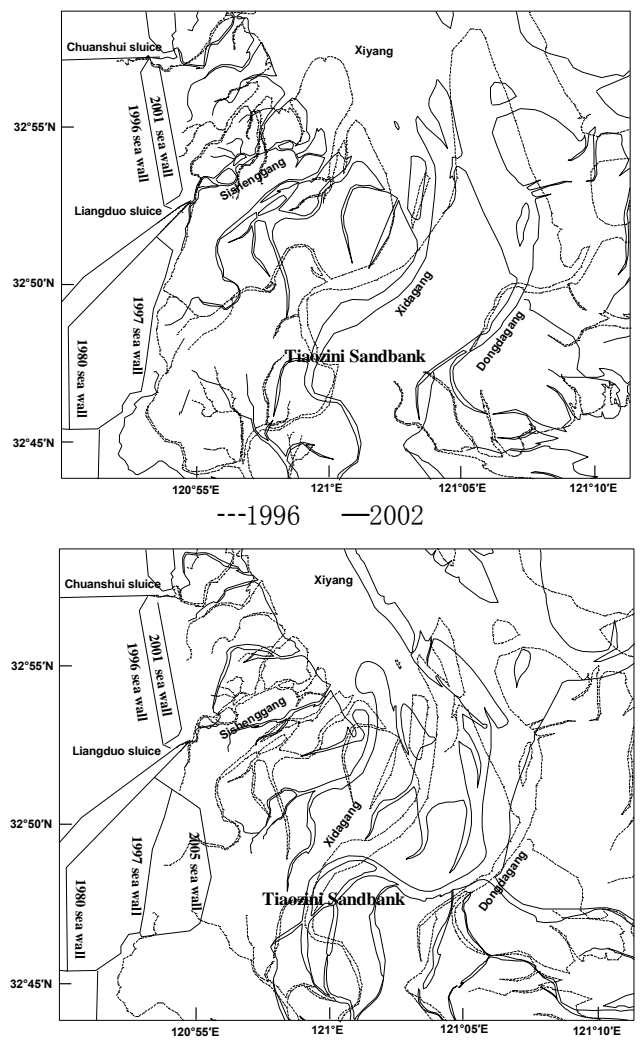

$---2002 \quad-2006$
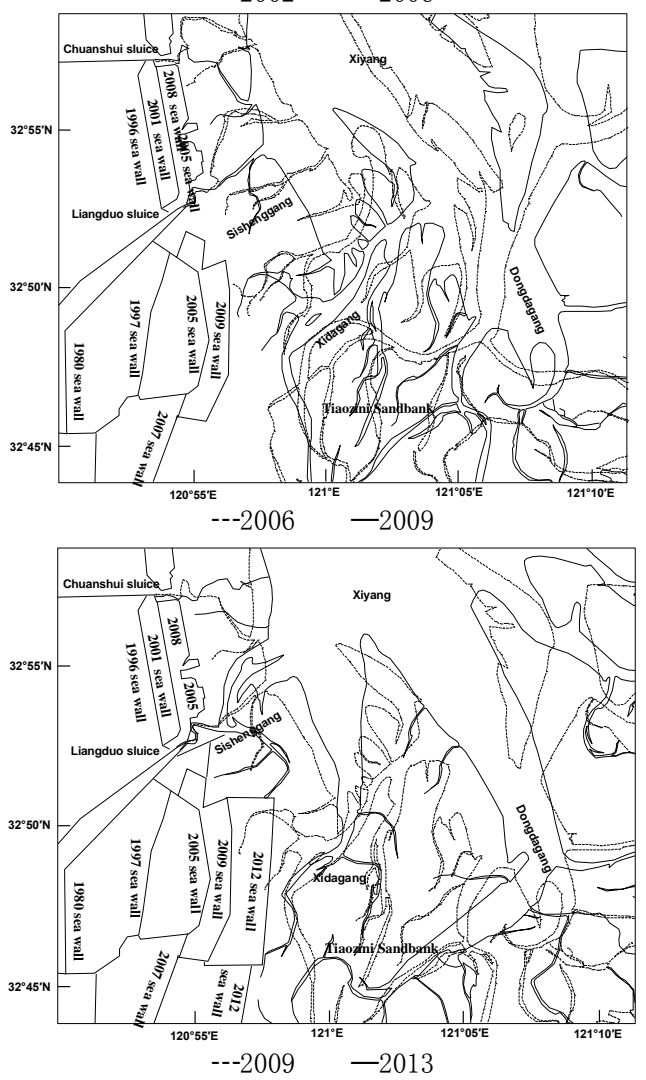

Fig. 5. development of the tidal creeks

\section{CONCLUSIONS}

There were four larger tidal creeks distributing on the tidal flat out of the Liangduohe sluice. The north side is the tidal channel of the Chuanshuigang sluice and the south side is the Erfenshui tidal ridges on the Tiaozini sandbank. This four tidal creeks extend from the Spartina angilica tidal flat, mud flats, silt-sand flats to the Xiyang tidal channel. So the tidal flat is divided into four tidal basins. The tidal current was strong and the suspended sediment concentration was high. The tidal flux and suspended sediment flux transported anticlockwise to the outer sea area of the Radial Sand ridges. It showed that the tidal flat has eroded in recent years. The periodic migration of the tidal creek was the main factors to control the development of the tidal flat. The area of the tidal basin decreased for the reclamation in recent years. The hydrodynamics of the tidal creeks became more intense, which caused the erosion of the tidal flat.

\section{ACKNOWLEDGMENT}

Financial support to the study is provided by the National Natural Science Foundation of China (grant nos. 40806018), National science and technology support plan (grant nos. 2012BAB03B01), Fundamental Research Funds for the Central Universities (grant nos. 2009B09814), Science and Technology Project of Dongtai (grant nos. DT201204). The author wish to thank Cai Hui, Ma Hongjiao, Sun Dianhong and Lin Xiang who participated in the field work.

\section{REFERENCES}

[1] Ren Ren, M.E., 1986. Tidal mud flat. In: Ren, M.E. (Ed.), Modern Sedimentation in the Coastal and Nearshore Zones of China. China Ocean Press, Beijing, pp. 78-127.

[2] Yang, J.H., 1982. Sedimentation on intertidal mudflats near Wanggang of Dafeng, Jiangsu Province. M.Sc. Thesis, Nanjing University, China (in Chinese).

[3] Allen, J.R.L., 2000. Morphodynamics of Holocene salt marshes: a review sketch from the Atlantic and Southern North Sea coasts of Europe. Quaternary Science Reviews 19, 1155-1231.

[4] Kragtwijk, N.G., Zitman T.J., Stive M.J.F., Wang Z.B., 2004. Morphological response of tidal basins to human interventions. Coastal Engineering, Vol.51, 3: 207-221

[5] Chen Jun, Wang Yigang, Wei Xiao-qing, Zhou Yong, 2011. Hydrodynamic-morphodynamic characteristics and evolution tendency of the Erfenshui water-dividing beach ridge of the Tiaozini tidal sandbank, Jiangsu coast, China. Journal of hydraulic engineering, 4: 108-114

[6] Chen Jun, WangYigang, Cai Hui. 2010. Profile characteristics study of the Jiangsu coast. Ocean Engineering. Vol.28 (4): 9096. 